\title{
BMJ Open Phase 2, randomised placebo-controlled trial to evaluate the efficacy and safety of an anti-GM-CSF antibody (KB003) in patients with inadequately controlled asthma
}

\author{
Nestor A Molfino, ${ }^{1}$ Piotr Kuna, ${ }^{2}$ Jonathan A Leff, ${ }^{3}$ Chad K Oh, ${ }^{4}$ Dave Singh, ${ }^{5}$ \\ Marlene Chernow, ${ }^{1}$ Brian Sutton, ${ }^{6}$ Geoffrey Yarranton ${ }^{1}$
}

To cite: Molfino NA, Kuna $P$, Leff JA, et al. Phase 2 , randomised placebocontrolled trial to evaluate the efficacy and safety of an antiGM-CSF antibody (KB003) in patients with inadequately controlled asthma. BMJ Open 2016:6:e007709.

doi:10.1136/bmjopen-2015007709

- Prepublication history and additional material is available. To view please visit the journal (http://dx.doi.org/ 10.1136/bmjopen-2015007709).

Received 19 January 2015 Revised 23 October 2015 Accepted 29 October 2015

CrossMark

For numbered affiliations see end of article.

Correspondence to Dr Nestor A Molfino; nestor.molfino@gmail.com

\section{ABSTRACT}

Objectives: We wished to evaluate the effects of an antigranulocyte-macrophage colony-stimulating factor monoclonal antibody (KB003) on forced expiratory volume in $1 \mathrm{~s}\left(\mathrm{FEV}_{1}\right)$, asthma control and asthma exacerbations in adult asthmatics inadequately controlled by long-acting bronchodilators and inhaled/ oral corticosteroids.

Settings: 47 ambulatory asthma care centres globally. Primary outcome measures: Change in $\mathrm{FEV}_{1}$ at week 24.

Participants: 311 were screened, 160 were randomised and 129 completed the study.

Interventions: 7 intravenous infusions of either $400 \mathrm{mg} \mathrm{KB003}$ or placebo at baseline and weeks 2, 4, 8, 12, 16 and 20.

Primary and secondary outcome measures: FEV at week 24, asthma control, exacerbation rates and safety in all participants as well as prespecified subgroups.

Main results: In the $\mathrm{KB} 003$ treated group, $\mathrm{FEV}_{1}$ at week 24 improved to $118 \mathrm{~mL}$ compared with $54 \mathrm{~mL}$ in the placebo group $(p=0.224)$. However, $F V_{1}$ improved to 253 vs $26 \mathrm{~mL}$ at week 24 ( $p=0.02)$ in eosinophilic asthmatics (defined as $>300$ peripheral blood eosinophils/mL at baseline) and comparable improvements were seen at weeks $20(p=0.034)$ and $24(p=0.077)$ in patients with $\mathrm{FEV}_{1}$ reversibility $\geq 20 \%$ at baseline and at weeks $4(p=0.029), 16(p=0.018)$ and $20(p=0.006)$ in patients with prebronchodilator $\mathrm{FEV}_{1} \leq 50 \%$ predicted at baseline. There were no effects on asthma control or exacerbation rates. The most frequent adverse events in the KB003 group were rhinosinusitis and headache. There was no significant difference in antidrug antibody response between placebo and treated groups. There were no excess infections or changes in biomarkers known to be associated with the development of pulmonary alveolar proteinosis.

Conclusions: Higher doses and/or further asthma phenotyping may be required in future studies with KB003.

\section{Strengths and limitations of this study}

- First randomised study in asthmatics with an antigranulocyte-macrophage colony-stimulating factor (GM-CSF) monoclonal antibody.

- Prespecified subgroups showed a significant response in forced expiratory volume in $1 \mathrm{~s}$.

- Not dose ranging.

- Not powered to detect differences in exacerbation rates.

- GM-CSF not measured in blood or sputum to clearly identify responders prospectively.

Trial registration number: NCT01603277; Results.

\section{INTRODUCTION}

Asthma is a chronic disease characterised by airway inflammation, airway hyperresponsiveness and episodic bronchoconstriction. The exact etiopathogenesis of asthma is not entirely understood, and inhaled corticosteroids (ICS) are the mainstay of therapy. Some patients with asthma show little or no benefit from corticosteroids even at high doses ${ }^{1}$ and have higher morbidity resulting in higher costs of care. ${ }^{2}$

Studies of induced sputum and airway biopsies have described two phenotypes of severe asthma, eosinophilic and neutrophilic, based on the relative number of cells present in the samples, ${ }^{3-5}$ and studies of peripheral blood of asthmatics suggest four inflammatory patterns according to eosinophil and neutrophil cut values. ${ }^{6}{ }^{6}$ Development of targeted therapies for asthma and phenotypespecific clinical trials has raised interest in the eosinophilic phenotype in particular. ${ }^{8} 9$ 
It is generally believed that the eosinophilic phenotype has a predominantly Th2 pathogenesis, while neutrophilic asthma is associated more frequently with Th17/ Th1 immune responses. ${ }^{10}{ }^{11}$ Granulocyte-macrophage colony-stimulating factor (GM-CSF) is a cytokine secreted by macrophages, $\mathrm{T}$ cells, mast cells, endothelial cells and fibroblasts that were initially described as haematopoietic growth factor. It is now understood that GM-CSF is a cytokine that plays a role in the activation, differentiation and survival of adaptive and innate immune cells including granulocytes, macrophages, dendritic cells and lymphocytes. GM-CSF is produced in small amounts by normal lung epithelium but in increased amounts by lung epithelial cells in asthmatics. ${ }^{12}$ Endobronchial allergen challenge in asthmatics results in increased GM-CSF immunoreactivity in lymphocytes and alveolar macrophages. ${ }^{13}$ GM-CSF levels are also higher in sputum, bronchoalveolar lavage fluid and bronchial tissue in individuals with asthma and chronic obstructive pulmonary disease. ${ }^{14}{ }^{15}$ Reduced eosinophil and neutrophil apoptosis correlates with increased lung inflammatory cell numbers and severity of asthma, ${ }^{16}{ }^{17}$ and GM-CSF has been shown to be an antiapoptotic factor for both these cell types. ${ }^{18}$ GM-CSF may be a key mediator in the recruitment, activation and maintenance of both these cell types in asthmatic airways ${ }^{15} 171920$ because it seems to cross the boundaries between Th2 and Th17/Th1 immunity suggesting it has a role in eosinophilic and neutrophilic asthma. $^{2} 52122$ In addition, GM-CSF production by peripheral blood mononuclear cells from corticosteroid-resistant asthmatic individuals is insensitive to corticosteroid inhibition, ${ }^{23}$ and animal data using anti-GM-CSF antibodies support the role of GM-CSF in airway disease. ${ }^{24-26}$

KB003 is a novel, high-affinity, recombinant IgG1א monoclonal antibody targeting GM-CSF. It neutralises GM-CSF activity by blocking its binding to GM-CSF cell surface receptors. Studies in non-human primates administered KB003 doses as high as $100 \mathrm{mg} / \mathrm{kg}$ showed no toxicology findings including lack of foamy macrophages in the lungs, which are a prodromic indicator of pulmonary alveolar proteinosis (PAP). Although circulating anti-GM-CSF antibodies have been found in otherwise healthy volunteers, ${ }^{27} 28$ the presence of such antibodies appears to be associated with the development of PAP. ${ }^{29}$ Yet, previous single-dose phase $1 \mathrm{~b}$ studies with KB002 (the predecessor to KB003) in asthmatics and in patients with rheumatoid arthritis showed trends in improvements in forced expiratory volume in $1 \mathrm{~s}\left(\mathrm{FEV}_{1}\right)$ or Disease Activity Score using the 28 joint count, respectively, without any safety concerns.

In view of the positive trends in efficacy and an acceptable safety profile after a single dose, we speculated that multiple doses of KB003 would be beneficial in treating patients with severe asthma. As such, we conducted a randomised, double-blind, placebo-controlled trial in moderate to severe asthmatics to assess the potential benefits and safety profile resulting from neutralisation of GM-CSF with KB003 over a 24-week period.

\section{METHODS}

\section{Study population and design}

The present study was a phase 2 randomised, doubleblind, placebo-controlled, parallel-group, repeat-dose study over 36 weeks (including a 20-week treatment period and screening and follow-up periods) to evaluate the safety, tolerability and efficacy of KB003 in adults with asthma inadequately controlled (defined by an asthma control questionnaire (ACQ) $>1.5$ at baseline) despite receiving treatment with long-acting $\beta_{2}$ agonists (LABA) and inhaled and/or oral corticosteroids. The study was approved by institutional review boards (Western Institutional Review Board on 2 July 2012approval \# 20120727, and Quorum review IRB on 18 July 2012 Quorum file \# 27264). Eligible participants had physician-diagnosed asthma, a per cent predicted $\mathrm{FEV}_{1}$ between $40 \%$ and $80 \%$, and a history of at least two asthma exacerbations in the prior year. All participants underwent a screening and run-in period of 2-4 weeks, during which baseline asthma control and adherence with study procedures and concomitant ambulatory medications were determined. During the run-in period, reversibility of airway obstruction $(\geq 12 \%$ improvement in $\mathrm{FEV}_{1}$ ) with short-acting $\beta_{2}$ agonists (SABA) was required, and baseline chest X-rays and immunoglobulin E levels were obtained. Participants who met all protocol-specified study entry criteria were randomised in a 1:1 ratio to receive $400 \mathrm{mg} \mathrm{KB} 003$ or placebo. Study drug was administered intravenously over approximately $60 \mathrm{~min}$ at weeks $0,2,4,8,12,16$ and 20 . Subsequent follow-up visits took place at weeks 24 (primary efficacy end point) and 28. At week 32, a phone interview was conducted to collect adverse events (AEs) information. A schema of the study design is provided in figure 1.

Throughout the study, medical history, concomitant medication use, physical examinations, arterial oxygen saturation $\left(\mathrm{SaO}_{2}\right)$, and clinical laboratory analyses (haematology, urinalysis and chemistry, including surfactant protein D (SP-D)) were obtained. In addition, pregnancy tests for females, blood samples for pharmacokinetic (PK) and anti-KB003 antibody determinations, ECGs, and AEs were collected. To monitor asthma, lung function (spirometry and daily peak flow rates), asthma exacerbations, ACQ asthma symptoms and rescue bronchodilator use (daily diary) were collected. The study was overseen by an independent Data Safety and Monitoring Committee, the purpose of which was to act in an advisory capacity to monitor the safety of the 160 participants enrolled in the study.

\section{End points}

The primary objective of the study was to evaluate the efficacy of $\mathrm{KB} 003$ on lung function in patients with 
Figure 1 Study schema: thick arrows denote dosing with KB003 or placebo; thin arrow denotes the primary end point assessment (forced expiratory volume in $1 \mathrm{~s}$ ); $\mathrm{a}=$ week 32 visit was a phone call.

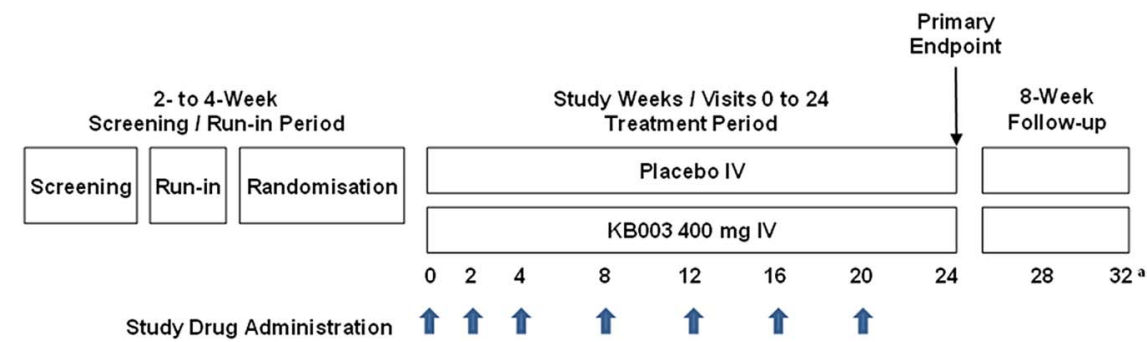

Study Drug Administration asthma inadequately controlled by LABA and inhaled/ oral corticosteroids, as measured by changes in prebronchodilator $\mathrm{FEV}_{1}$ at week 24. Secondary objectives of the study were to evaluate asthma exacerbation rates, peak expiratory flow rate (PEFR), ACQ scores, asthma symptoms, rescue short-acting bronchodilator use, safety and tolerability, PK and immunogenicity of KB003.

\section{Sample size and other statistical considerations}

On the basis of a previous study with anti-GM-CSF in asthmatics (unpublished), and to detect a difference between the placebo and KB003 groups of $6.7 \%$ in per cent predicted $\mathrm{FEV}_{1}$ over 24 weeks (80\% statistical power, $\alpha=0.05$, 2-tailed test), a sample size of 60 participants per group was needed. To account for an anticipated $15 \%$ dropout rate during the 24 weeks of the randomised treatment period, the target enrolment was 150 participants (75 participants per group). With respect to the exacerbation rate over 24 weeks, there was $80 \%$ statistical power to detect a difference of 0.5 exacerbations per participant between the placebo and KB003 treatment groups $(\alpha=0.05$, 2-tailed test; $15 \%$ dropouts over 24 weeks), assuming approximately 1.0 exacerbation per participant over 24 weeks was expected as seen in two previous clinical studies with similar asthma populations. ${ }^{3} 30$

The Full Analysis Set (FAS) consisted of all randomised participants with a baseline value who received at least 1 dose of randomised treatment and had at least 1 treatment period measurement of lung function. The FAS was the primary analysis population and was used for the analysis of the primary end point. The Evaluable Set (ES) consisted of all participants included in the FAS who received at least four consecutive doses of study drug and had no major protocol deviations. The ES was used for efficacy analyses in prespecified subgroups.

For spirometry variables, the baseline value was defined as the last non-missing prebronchodilator value collected prior to the first dose of study medication. For daily variables (morning PEFR, asthma symptom score, rescue SABA use), the baseline average value was defined as the average of the last 7 days prior to randomisation (including the value collected predose at the randomisation visit (week 0). For the ACQ, the baseline value was the one obtained at the randomisation visit (week 0). Missing data were not imputed or replaced in any analyses except the jump to reference (J2R) imputation for the secondary analyses of spirometry parameters at week 24. Missing week 24 values were imputed using the average week 24 value in the placebo group and were analysed using an analysis of covariance (ANCOVA) model.

The summaries of absolute and per cent predicted $\mathrm{FEV}_{1}$ at baseline and at weeks 2, 4, 8, 12, 16, 20 and 24, and the analyses of the change from baseline in each parameter at week 24 using a linear mixed-effects model, were repeated for the following seven prespecified subgroups: (1) atopic asthma versus non-atopic asthma (atopy defined by at least 1 allergen in a panel of common allergens had a value $\geq 100 \mathrm{kUA} / \mathrm{L}$; conversely, participants with values $<100 \mathrm{kUA} / \mathrm{L}$ for common allergens tested were considered to have nonatopic asthma), (2) baseline blood eosinophils $<0.3$ vs $\geq 0.3 \mathrm{GI} / \mathrm{L}$, (3) medium-dose versus high-dose ICS (determined in accordance with the Global Initiative for Asthma guidelines (http://www.ginasthma.org), (4) two asthma exacerbations versus $>2$ asthma exacerbations in the previous year, (5) high reversibility at study entry $(<20 \%$ vs $\geq 20 \%)$, (6) prebronchodilator per cent predicted $\mathrm{FEV}_{1}$ at study entry $(\leq 50 \%$ vs $>50 \%)$ and (7) history of smoking versus never-smoked (smokers were defined as smoking $\leq 10$ pack-year within the 12 months prior to screening).

All planned subgroup analyses were performed using the ES.

\section{Efficacy analysis of absolute and per cent predicted $\mathrm{FEV}_{1}$} The primary analysis of the change from baseline in $\mathrm{FEV}_{1}$ over 24 weeks used a linear mixed-effects model with change from baseline in $\mathrm{FEV}_{1}$ as the dependent variable. The fixed terms in the model accounted for treatment, region (North America, Europe/Australia), and the baseline $\mathrm{FEV}_{1}$ value. The random effects in the model accounted for the repeated measurements within each study visit. PROC MIXED in SAS was used to analyse the data. ESTIMATE statements were used to obtain $\mathrm{p}$ values, and two-sided $95 \%$ CIs for the least square (LS) mean difference between KB003 and placebo at week 24 . For the primary analysis, there was no data imputation. The primary efficacy analysis was performed using the FAS, and repeated using the ES.

Secondary analyses of $\mathrm{FEV}_{1}$ included analysis of the change from baseline at weeks $2,4,8,12,16$ and 20 using the linear mixed-effects model as described above, 
and an analysis of the change from baseline at week 24 using J2R to impute missing values at week 24 using an ANCOVA model with terms for treatment, region (North America, Europe/Australia) and the baseline value. The change from baseline in $\mathrm{FEV}_{1}$ at weeks 2, 4, 8, 12, 16 and 20 were analysed in the FAS and ES using the linear mixed-effects model and the ANCOVA model with J2R imputation as described above.

\section{Asthma exacerbations}

At every study visit, participants were assessed for asthma exacerbations experienced since the last visit. Asthma exacerbations were defined by meeting one or more of the following criteria: (1) use of systemic corticosteroids (tablets, suspension or injection) for at least 3 days to treat worsening of asthma symptoms; (2) hospitalisation or emergency room, urgent care or physician visit for asthma worsening, requiring systemic corticosteroids or (3) in those participants taking oral corticosteroids (OCS) at study entry, at least a doubling of the OCS dose for at least 3 consecutive days. Courses of OCS separated by 7 days or more were treated as separate exacerbations.

The number and percentage of participants reporting a protocol-defined asthma exacerbation are presented by treatment and visit using the FAS. The protocoldefined exacerbation rates were compared using Poisson regression while accounting for the possibility of hyper-Poisson variability using PROC GENMOD in SAS, with fixed terms for treatment and region (North America, Europe/Australia). In addition, the number of participants with at least one protocol-defined exacerbation reported after the initiation of study drug was analysed using a logistic regression model with fixed terms for treatment and region (North America, Europe/ Australia). Cox's proportional hazards model was used to compare the treatment groups with respect to time to first protocol-defined exacerbation using the ES. PROC PHREG in SAS was used to analyse the data. Participants who did not report a protocol-defined asthma exacerbation were treated in the model as censored observations and were censored at the date of the week 24 visit. The independent variables in the model were treatment group and region (North America, Europe/Australia). Kaplan-Meier plots were produced using PROC LIFETEST in SAS for visual assessment of the survival curves.

\section{Other secondary end points}

The following secondary end points were collected and analysed in the study: (1) PEFR using the highest recorded value of three acceptable efforts, the average morning PEFR (defined as the highest value of 3 acceptable efforts) at each visit being calculated for each participant over the prior week; (2) asthma symptoms score using the average of the responses to four daytime asthma symptom questions in the daily diary, the average daily symptom score (defined as the average of the responses to 4 questions in the daily dairy) at each visit being calculated for each participant over the prior week; (3) nocturnal awakenings using the responses to the question 'Did you wake up with asthma symptoms?' in the daily diary, the total number of nights with a nocturnal awakening at each visit being calculated for each participant over the prior week; (4) rescue short-acting bronchodilator (SABA and/or short-acting antimuscarinic agent (SAMA)) use using the daily number of puffs captured in the daily diary, the average daily number of puffs of rescue short-acting bronchodilator (SABA and/ or SAMA) at each visit being calculated for each participant over the prior week and (5) ACQ score ${ }^{31}$ using the first five items related to asthma symptoms calculated for each participant at each visit, the ACQ5 score being calculated for each participant at each visit. For each of these secondary end points, the change from baseline at weeks $2,4,8,12,16,20$ and 24 was analysed using a linear mixed-effects model. The fixed terms in the model accounted for treatment, region (North America, Europe/Australia) and the baseline values. The random effects in the model accounted for the repeated measurements within each study participant. $p$ Values for the LS mean difference between KB003 and placebo by visit were calculated along with two-sided $95 \%$ CIs.

\section{Pharmacokinetics analysis}

A KB003 PK model was developed using data from an earlier study (study KB003-04) and a phase 1 study conducted in healthy adult volunteers (study KB003-01). In study KB003-04, blood for serum KB003 assay was collected from a subset of participants prior to dose administration at weeks $0,4,8,12,16$ and 20; at approximately $1 \mathrm{~h}$ after the end of infusion at weeks 0 and 20; and during a scheduled clinic visit at weeks 24 and 28. In study KB003-01, a single intravenous infusion of 1, 3, or $10 \mathrm{mg} \mathrm{KB} 003$ per $\mathrm{kg}$ of body weight was administered over $1 \mathrm{~h}$. The PK of KB003 was described adequately by a two-compartment linear model with first-order elimination. Body weight did not influence the PK of KB003. The individual post hoc estimates from the population PK model were used to derive the individual exposure metrics (area under the concentration-time curve (AUC), maximum observed concentration $\left(\mathrm{C}_{\max }\right)$ and half-life $\left.\left(\mathrm{T}_{1 / 2}\right)\right)$ of KB003.

\section{Immunogenicity analysis}

A validated electrochemiluminescence assay method was used for sample testing. The determination of antidrug antibodies consisted of three sequential steps: (1) screening, (2) confirmation and (3) titer determination. A predose/postdose ratio was evaluated for the combined placebo and KB003 groups. This ratio established what could be considered a significant increase in postdose signal response from the corresponding prefirst dose sample (emergent immune response). In order to compare predose and postdose samples analysed on different plates, the screening signal response was 
normalised against the pooled negative control signal response specific to the plate where the sample was analysed. Using this calculated normalised signal response, each participant in the placebo and KB003 groups was analysed for a predose/postdose ratio for all postdose time points. A $95 \%$ upper limit was established using all the predose/postdose ratio data. Any sample with a predose/postdose ratio above the $95 \%$ upper limit was considered a meaningful increase in signal response. Using the calculated predose/postdose ratio, samples and participants were identified that corresponded to an increase in signal response from baseline.

For AEs with $>5 \%$ frequency, Fisher exact tests were applied to compare groups, without any multiplicity adjustment for the significance level.

\section{RESULTS}

In total, 311 asthmatics were screened across 47 clinical sites between July 2012 and June 2013, of whom 160 were enrolled in the study. Of these, 128 participants completed the study: 111 completed all study visits including the week 32 follow-up visit and 107 received all seven doses of either study drug or placebo. Subject dispositions are summarised in figure 2 and table 1 . All participants who were randomised in the study received at least one dose. Participants were randomly assigned to study treatment in accordance with the randomisation schedule. The randomisation scheme was stratified according to the use of chronic OCs (yes, no) and region (North America, Australia, Europe). The protocol included an expectation that between $20 \%$ and $40 \%$ of participants would be on treatment with both chronic oral and ICS in the study; however, there were actually fewer participants than anticipated in this category (approximately 10\%). Therefore, the use of chronic OCs (yes, no) strata was not included in analyses as a factor in models or as a subgroup variable. In addition, due to the small number $(n=13)$ of participants randomised in Australia, participants randomised in Australia were combined with participants randomised in Europe, where region is indicated as a factor in analysis models. Participants were randomised in a ratio of $1: 1$ (400 mg KB003: placebo) at the randomisation visit, the day of first infusion (week 0 ).

Demographics and baseline characteristics for the FAS are summarised in table 2. The demographic and key baseline characteristics across the analysis sets and across treatment groups both within and across the analysis sets were comparable. All participants were treated with LABA/ICS, and $10 \%$ of all participants also received OCS. The doses of ICS/LABA, exacerbation rates as well as eosinophils and doses of ICS/LABA were comparable between groups. Comorbidities were not collected and exacerbation rates as well as eosinophils were not different between groups at baseline.

Change from baseline by visit in absolute and per cent predicted prebronchodilator $\mathrm{FEV}_{1}$ in $\mathrm{KB} 003$ and placebo groups in the FAS and ES over 24 weeks are presented in figure $3 \mathrm{~A}, \mathrm{~B}$, respectively. At week 24 , the primary end point, improvement in mean $\mathrm{FEV}_{1}$ in the $\mathrm{KB} 003$ group was $118 \mathrm{~mL}$ compared with $54 \mathrm{~mL}$ in the placebo group $(\mathrm{p}=0.224)$.

There were no differences in mean cumulative asthma exacerbations by visit over 24 weeks in the KB003 and placebo groups in the FAS and ES; data for the FAS are presented in figure 4 . There were no differences with placebo in asthma exacerbation rates over 24 weeks $(\mathrm{KB} 003=0.398$ vs placebo=0.349). In addition, no drug effect was observed on PEFR, asthma symptoms,

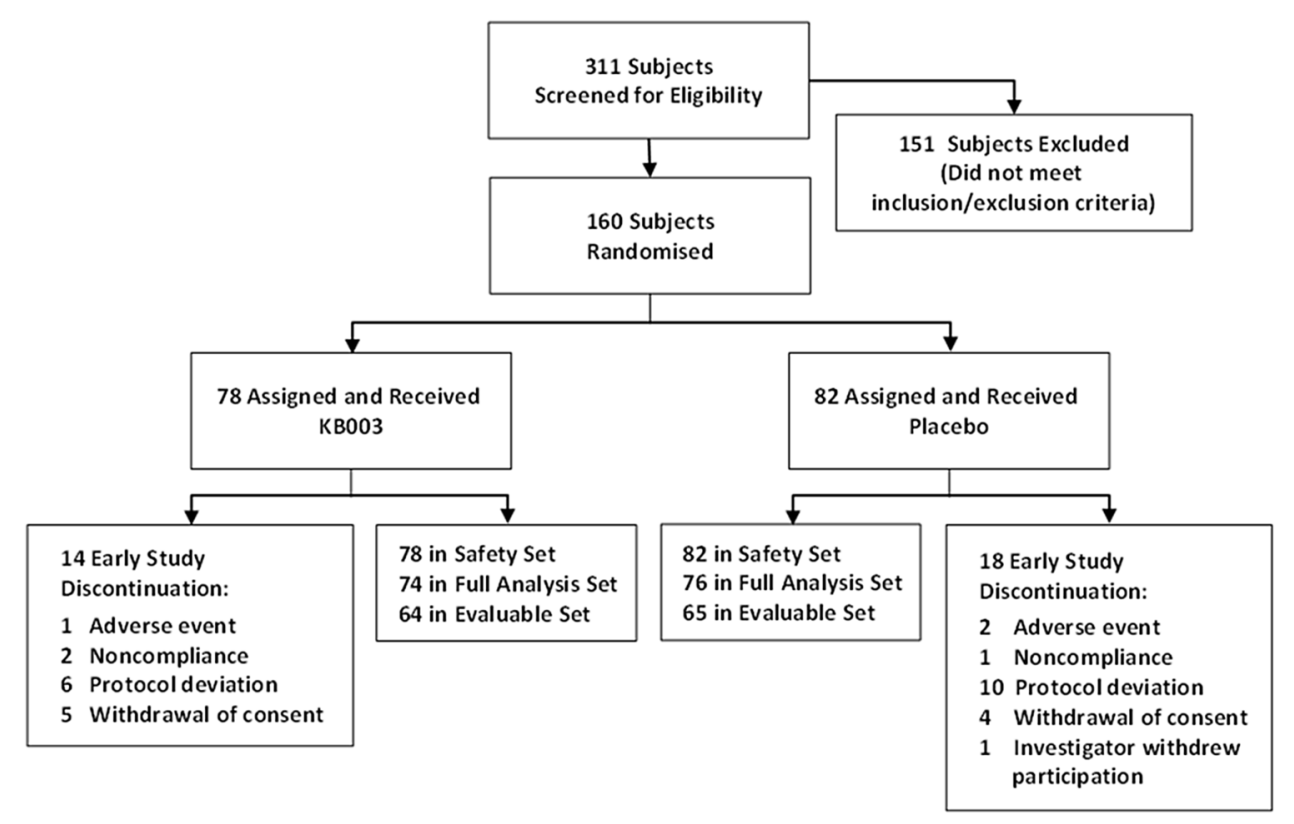

Figure 2 Participant disposition during the trial (see text for details). 
Table 1 Disposition of participants

\begin{tabular}{|c|c|c|}
\hline & $\begin{array}{l}\text { KB003 } \\
(n=78)\end{array}$ & $\begin{array}{l}\text { Placebo } \\
(n=82)\end{array}$ \\
\hline Full Analysis Set * & $74(94.9)$ & $76(92.7)$ \\
\hline Safety Set† & $78(100.0)$ & $82(100.0)$ \\
\hline Evaluable Setł & $64(82.1)$ & $65(79.3)$ \\
\hline $\begin{array}{l}\text { Received all } 7 \text { doses of study } \\
\text { drug }\end{array}$ & $56(71.8)$ & $51(62.2)$ \\
\hline $\begin{array}{l}\text { Completed all study visits } \\
\text { including week } 32 \text { visit }\end{array}$ & $57(73.1)$ & $54(65.9)$ \\
\hline Discontinued the study early & $14(17.9)$ & $18(22.0)$ \\
\hline \multicolumn{3}{|c|}{ Primary reason for early study discontinuation } \\
\hline Adverse event & $1(7.1)$ & $2(11.1)$ \\
\hline $\begin{array}{l}\text { Non-compliance/lost to } \\
\text { follow-up }\end{array}$ & $2(14.3)$ & $1(5.6)$ \\
\hline Pregnancy & 0 & 0 \\
\hline Protocol deviation & $6(42.9)$ & $10(55.6)$ \\
\hline Consent withdrawal & $5(35.7)$ & $4(22.2)$ \\
\hline Death & 0 & 0 \\
\hline $\begin{array}{l}\text { Investigator withdrew } \\
\text { participation from study }\end{array}$ & 0 & $1(5.6)$ \\
\hline
\end{tabular}

Percentages for primary reason for early study discontinuation are based on the number of discontinued participants in each treatment group. All other percentages are based on the number of randomised participants in each treatment group.

*The Full Analysis Set consisted of all randomised participants with a baseline value who received at least 1 dose of study drug and had at least 1 treatment period measurement.

†The Safety Set consisted of all randomised participants who received at least 1 dose of study drug.

\#The Evaluable Set consisted of all participants included in the

Full Analysis Set who received at least 4 consecutive doses of study drug and had no major protocol deviations.

nocturnal awakenings, rescue SABA use, ACQ scores or peripheral blood eosinophilia in the study population.

\section{Examination of predefined subgroups}

Eosinophilic asthma: In participants with baseline blood eosinophils $\geq 0.3 \mathrm{GI} / \mathrm{L}$, there was a significant $\mathrm{FEV}_{1}$ improvement in the KB003 group at week 24 (figure 5A): LS mean: KB003, 0.253 L; placebo, $0.026 \mathrm{~L}$ (95\%, 2-sided CI 0.038 to 0.414 ), $\mathrm{p}=0.020$.

Prebronchodilator $\mathrm{FEV}_{1} \leq 50 \%$ : In participants with prebronchodilator $\mathrm{FEV}_{1} \leq 50 \%$ at study entry, there were significant $\mathrm{FEV}_{1}$ improvements in the $\mathrm{KB} 003$ group at week 4 (figure 5B): LS mean: KB003, 0.187; placebo, -0.076 (95\%, 2-sided CI 0.029 to 0.498$), \mathrm{p}=0.029$, at week 16 : LS mean: KB003, 0.254; placebo, 0.013 (95\%, 2-sided CI 0.044 to 0.438$), \mathrm{p}=0.018$, and at week 20: LS mean: KB003, 0.279; placebo, -0.050 (95\%, 2-sided CI 0.100 to $0.559), \mathrm{p}=0.006$.

Highly reversible $F E V_{1}$ : In participants with $\geq 20 \%$ reversibility at study entry, there was a significant $\mathrm{FEV}_{1}$ improvement in the KB003 group at week 20 (figure 5C): LS mean: KB003, 0.202; placebo, 0.019 (95\%, 2-sided CI 0.015 to 0.353$), \mathrm{p}=0.034$ and a trend towards $\mathrm{FEV}_{1}$ improvement at week 24: LS mean: KB003, 0.191; placebo, 0.040 (95\%, 2-sided CI -0.01 to 0.320$)$, $\mathrm{p}=0.077$.
We found 10 participants (8 who received KB003) in whom the characteristics of eosinophilia, a low $\mathrm{FEV}_{1}$ at baseline, coupled with a history of $\geq 2$ exacerbations in the previous year, were associated with significant improvements in $\mathrm{FEV}_{1}$ (table 3) in six of eight participants, which were not accompanied by reductions of ACQ.

\section{Pharmacokinetics and immunogenicity}

The individual post hoc estimates from the PK model for KB003 parameters were as follows: AUC, $12488 \mu \mathrm{g}$ $\mathrm{h} / \mathrm{mL}$ (range 7486-18 244); median $\mathrm{T}_{1 / 2}, 706 \mathrm{~h}$ (range 530-883); $\mathrm{C}_{\max }, 69942 \mathrm{ng} / \mathrm{mL}$ (range 64 010-78 938) and $\mathrm{C}_{\max }$ at steady state $\left(\mathrm{C}_{\mathrm{max}-\mathrm{ss}}\right), 78074 \mathrm{ng} / \mathrm{mL}$ (range 67 837-90 988). Using a calculated predose/postdose ratio analysis, 7 of 77 participants in the KB003 group developed antibodies in response to KB003 compared with 4 of 77 participants in the placebo group.

\section{Safety profile}

Safety evaluations included all randomised participant who received at least one dose of randomised treatment. All $\mathrm{AE}$ variables were categorised and summarised using relative frequencies of the least $5 \%$ in any of the groups. Fisher exact tests were applied to compare groups, without any multiplicity adjustment for the significance level. AEs were coded using MedDRA V.16.1 and are summarised in table 4, and serious AEs (SAEs) are summarised in table 5. Infusion-related reactions were mild to moderate, affecting four participants in the KB003 group and two in the placebo group. All events were either self-limiting or were treated with medication and resolved without sequelae. Three participants discontinued study drug and withdrew from the study due to AEs: one participant in the KB003 group after hospitalisation for a suicide attempt, one on placebo because of hospitalisation for chronic septic arthritis, and a third, also on placebo, who was withdrawn from the study after receiving two doses of study drug due to non-serious infusionrelated reactions. One participant in the KB003 group experienced a decreased absolute neutrophil count (ANC) below $1.5 \times 10^{3} / \mu \mathrm{L}$ at week $16\left(1.42 \times 10^{3} / \mu \mathrm{L}\right)$, which returned to $1.92 \times 10^{3} / \mu \mathrm{L}$ (higher than baseline, $1.66 \times 10^{3} / \mu \mathrm{L}$ ) by week 20 after seven doses. The second participant, in the placebo group, was found to have a decreased ANC below $1.5 \times 10^{3} / \mu \mathrm{L}$ at week 20 $\left(1.23 \times 10^{3} / \mu \mathrm{L}\right)$ after receiving the last of the seven doses directed by the study protocol.

There was no difference between the KB003 and the placebo groups in SP-D, which has been described as a biomarker associated with the development of PAP. $^{32} 33$

\section{DISCUSSION}

In this 24-week study conducted in 160 adults with moderate to severe uncontrolled asthma, KB003 did not provoke improvement in prebronchodilator $\mathrm{FEV}_{1}$ in the 
Table 2 Demographics and baseline characteristics (Safety Set and Full Analysis Set)

\begin{tabular}{|c|c|c|c|c|}
\hline & \multicolumn{2}{|l|}{ Safety Set } & \multicolumn{2}{|l|}{ Full Analysis Set } \\
\hline & $\begin{array}{l}\text { KB003 } \\
(n=78)\end{array}$ & $\begin{array}{l}\text { Placebo } \\
(n=82)\end{array}$ & $\begin{array}{l}\text { KB003 } \\
(n=74)\end{array}$ & $\begin{array}{l}\text { Placebo } \\
(n=76)\end{array}$ \\
\hline \multicolumn{5}{|l|}{ Demographics } \\
\hline \multicolumn{5}{|l|}{ Age, years } \\
\hline Mean (SD) & $52.9(11.95)$ & $53.1(10.30)$ & $52.9(11.84)$ & $53.3(10.38)$ \\
\hline Median & 53.5 & 54.0 & 53.5 & 54.0 \\
\hline Range & $22-73$ & $19-75$ & $22-73$ & $19-75$ \\
\hline \multicolumn{5}{|l|}{ Gender, n (\%) } \\
\hline Female & $44(56.4)$ & $48(58.5)$ & $44(59.5)$ & $46(60.5)$ \\
\hline Male & $30(43.6)$ & 34 (41.5) & $30(40.5)$ & $30(39.5)$ \\
\hline \multicolumn{5}{|l|}{ Race, n (\%) } \\
\hline Asian & $2(2.6)$ & $3(3.7)$ & $2(2.7)$ & $2(2.6)$ \\
\hline Black or African American & $7(9.0)$ & $9(11.0)$ & $6(8.1)$ & $8(10.5)$ \\
\hline White & $69(88.5)$ & $69(84.1)$ & $66(89.2)$ & $65(85.5)$ \\
\hline Other & 0 & $1(1.2)$ & 0 & $1(1.3)$ \\
\hline \multicolumn{5}{|l|}{ Ethnicity, n (\%) } \\
\hline Hispanic or Latino & $4(5.1)$ & $7(8.5)$ & $4(5.4)$ & $6(7.9)$ \\
\hline Not Hispanic or Latino & $74(94.9)$ & $75(91.5)$ & $70(94.6)$ & $70(92.1)$ \\
\hline \multicolumn{5}{|l|}{ Baseline characteristics } \\
\hline \multicolumn{5}{|l|}{ Height, cm } \\
\hline Mean (SD) & 168.37 (9.986) & $167.31(8.477)$ & $167.97(9.891)$ & $166.93(8.405)$ \\
\hline Median & 167.80 & 167.57 & 167.0 & 167.25 \\
\hline Range & $148.0-190.5$ & $152.0-185.4$ & $148.0-188.0$ & $152.0-185.4$ \\
\hline \multicolumn{5}{|l|}{ Weight, kg } \\
\hline Mean (SD) & 83.05 (17.452) & $82.26(16.951)$ & 82.44 (17.551) & $82.49(17.006)$ \\
\hline Median & 81.35 & 82.44 & 79.55 & 82.70 \\
\hline Range & $42.6-120.0$ & $48.0-123.0$ & $42.6-120.0$ & $48.0-123.0$ \\
\hline \multicolumn{5}{|l|}{ BMI, kg/m² } \\
\hline Mean (SD) & $29.340(6.0031)$ & $29.365(5.6555)$ & 29.259 (6.0292) & $29.592(5.7388)$ \\
\hline Median & 29.209 & 29.440 & 29.008 & 29.560 \\
\hline Range & $13.46-46.99$ & $17.99-42.79$ & $13.46-46.99$ & $17.99-42.79$ \\
\hline \multicolumn{5}{|l|}{ Percentage predicted $\mathrm{FEV}_{1}$} \\
\hline Mean (SD) & $56.636(10.6441)$ & $56.483(10.8880)$ & $56.440(10.6499)$ & $57.638(9.5821)$ \\
\hline Median & 56.760 & 55.815 & 56.185 & 56.690 \\
\hline Range & $34.59-77.82$ & $25.09-77.45$ & $34.59-77.82$ & $39.81-77.45$ \\
\hline \multicolumn{5}{|l|}{$\mathrm{FEV}_{1}, \mathrm{~L}$} \\
\hline Mean (SD) & $1.774(0.5536)$ & $1.713(0.4678)$ & 1.752 (0.5425) & $1.736(0.4595)$ \\
\hline Median & 1.760 & 1.630 & 1.700 & 1.650 \\
\hline Range & $0.97-3.03$ & $0.69-3.10$ & $0.97-3.03$ & $1.09-3.10$ \\
\hline \multicolumn{5}{|l|}{ ACQ5 score } \\
\hline Mean (SD) & $2.86(0.705)$ & $2.87(0.763)$ & $2.84(0.711)$ & $2.89(0.786)$ \\
\hline Median & 2.86 & 2.86 & 2.86 & 2.86 \\
\hline Range & $1.6-4.3$ & $1.3-4.7$ & $1.6-4.3$ & $1.3-4.7$ \\
\hline
\end{tabular}

Percentages are based on the number of randomised participants in the Full Analysis Set or Safety Set in each treatment group. Baseline values are defined as the last non-missing values collected prior to first dose of study drug.

$A C Q$, Asthma Control Questionnaire; BMI, body mass index; $F V_{1}$, forced expiratory volume in $1 \mathrm{~s}$.

overall study population. We wished to explore $\mathrm{FEV}_{1}$ as primary end point for three reasons: (1) the size of the study would allow for statistical power, (2) the evidence collected on a previous phase $1 \mathrm{~b}$ study in asthmatics (unpublished) in which trends were seen in $\mathrm{FEV}_{1}$ improvements $(120 \mathrm{~mL})$ within 28 days and (3) because other biologics which reduce asthma exacerbations also improve $\mathrm{FEV}_{1}$ and improve asthma control. ${ }^{9}{ }^{34}$ Indeed, in this present study, we found significant $\mathrm{FEV}_{1}$ improvements in participants with peripheral blood eosinophils
$>300$ cells $/ \mathrm{mL}$, high $\mathrm{FEV}_{1}$ reversibility $(\geq 20 \%$ improvement following SABA use) or prebronchodilator $\mathrm{FEV}_{1}$ $\leq 50 \%$ at baseline. Given that the $\mathrm{FEV}_{1}$ response to biologics can be variable depending on the patient population $^{35-37}$ and, possibly, on the biological mechanism of action, the three prespecified phenotypic characteristics of peripheral blood eosinophilia, low baseline $\mathrm{FEV}_{1}$, and high acute reversibility postbronchodilators in a population with a history of frequent asthma exacerbations are markers of poorly controlled asthma. All participants in 

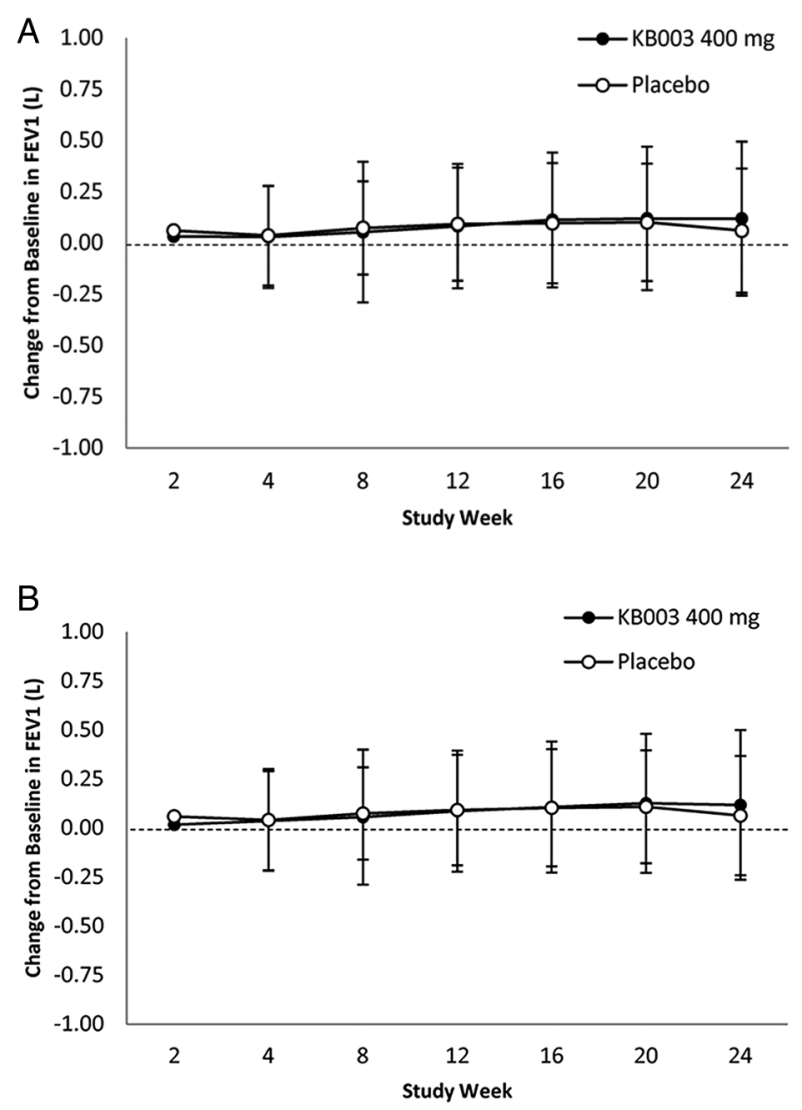

Figure 3 (A) Mean change $\pm S D$ in forced expiratory volume in $1 \mathrm{~s}\left(\mathrm{FEV}_{1}\right)$. At baseline: KB003 $n=74$; placebo $n=76$. Full Analysis Set (all participants who received at least 1 dose); (B) only participants who receive 4 doses of $\mathrm{KB} 003$ or placebo. At baseline: KB003 $n=64$; placebo $n=65$. Close circles $=$ KB003 recipients.

this study were receiving LABA and medium or high doses of ICS (some including OCS), but the changes in $\mathrm{FEV}_{1}$ were independent of the dose of corticosteroids

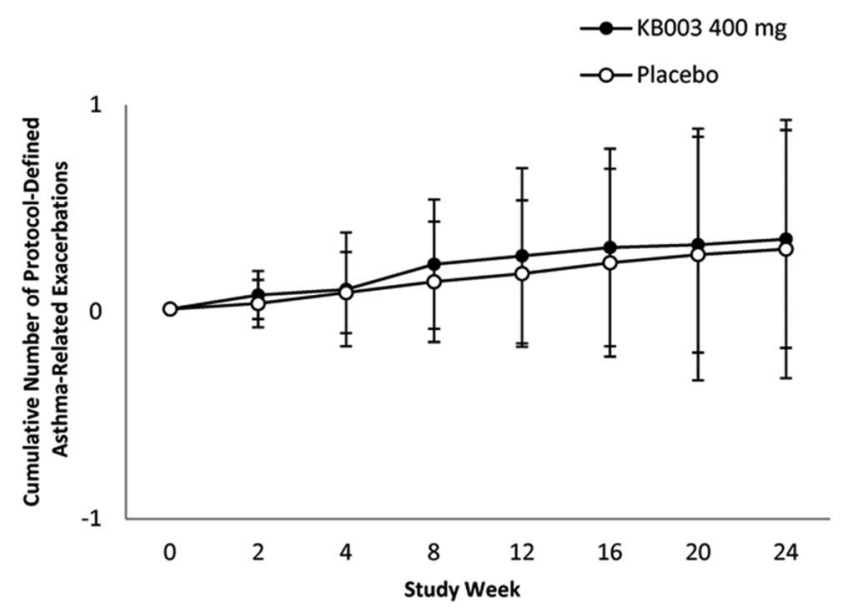

Figure 4 Cumulative number of exacerbations in participants who received at least one dose of KB003 or placebo. Close circles=KB003 recipients (see text for details) $\left(\mathrm{FEV}_{1}\right.$, forced expiratory volume in $1 \mathrm{~s}$; LS, least square).

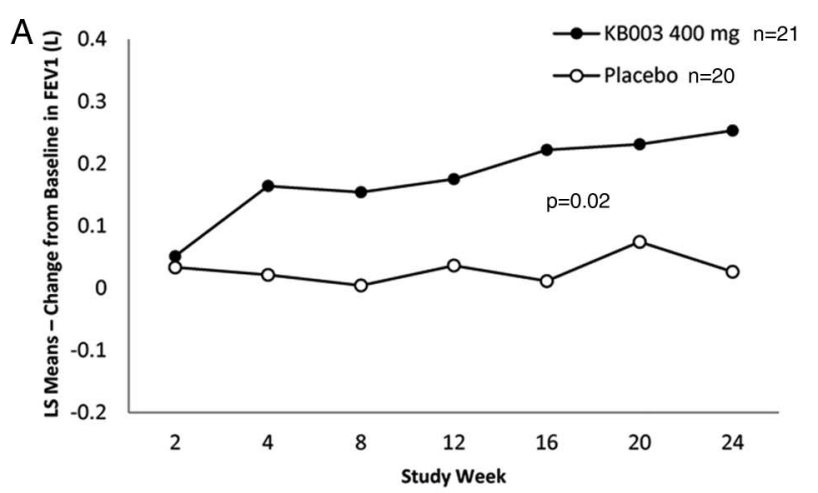

B
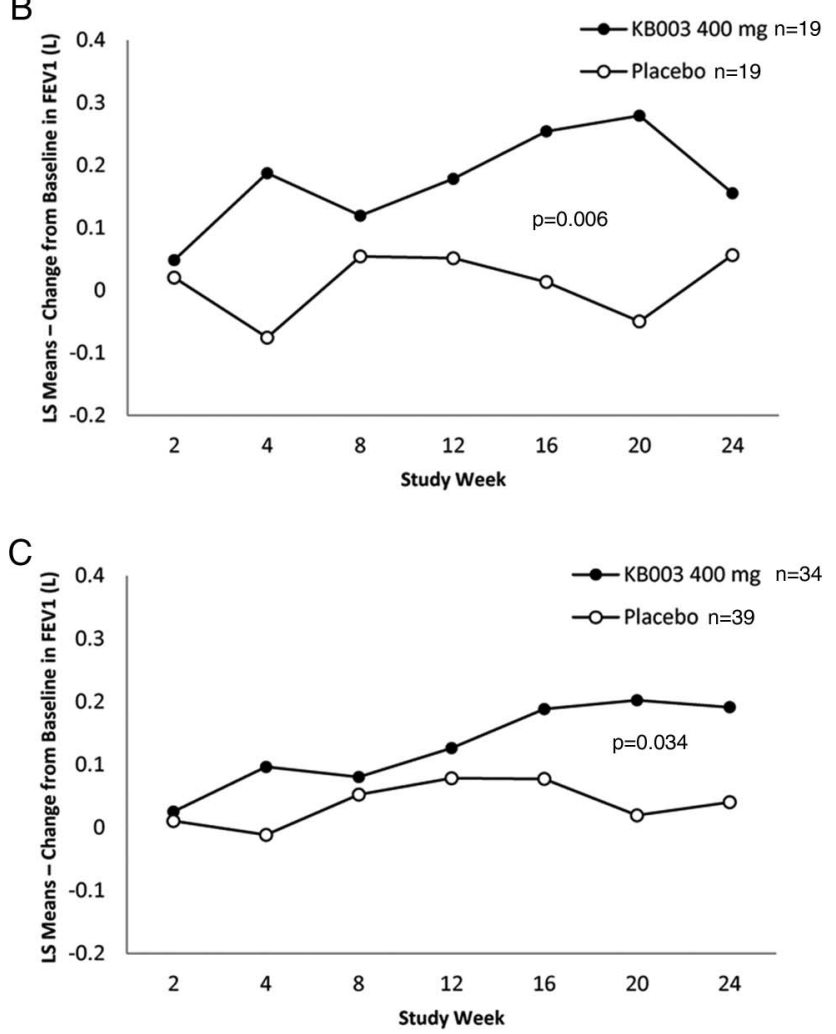

Figure 5 Changes from baseline in primary end point in three of the predetermined subgroups (see text for details). (A) Eosinophilic asthmatics at baseline; (B) severe airflow obstruction at randomisation and $(C)$ augmented postbronchodilator reversibility (>20\% improvement in $\mathrm{FEV}_{1}$ ) at baseline. Close circles $=\mathrm{KBO03}$ recipients $\left(\mathrm{FEV}_{1}\right.$, forced expiratory volume in $1 \mathrm{~s}$; LS, least square).

used by participants (data not shown). This suggests that the statistically significant $\mathrm{FEV}_{1}$ improvements seen are unlikely related to undertreatment with corticosteroids.

Although the $\mathrm{FEV}_{1}$ improvements were consistent over time, no improvements in asthma control or reduction in exacerbations were observed possibly due to the low exacerbation rate and the reduced small sample size used for these secondary analyses.

The reasons why $400 \mathrm{mg} \mathrm{KB} 003$ administered once monthly did not yield benefits in non-eosinophilic 
Table 3 FEV ${ }_{1}$ changes in participants with eosinophilia, airways reversibility at baseline and history of $>2$ asthma exacerbations in the previous year

\begin{tabular}{|c|c|c|c|c|c|c|c|c|}
\hline \multirow[b]{2}{*}{ Subject ID } & \multirow[b]{2}{*}{$\begin{array}{l}\text { Study } \\
\text { drug }\end{array}$} & \multirow[b]{2}{*}{$\begin{array}{l}\text { BMI }\left(\mathrm{kg} / \mathrm{m}^{2}\right) \\
\text { (Gender) }\end{array}$} & \multicolumn{3}{|l|}{ Baseline } & \multicolumn{3}{|l|}{ W24/ET } \\
\hline & & & $\begin{array}{l}\text { FEV }_{1} \% \\
\text { predicted (\%) }\end{array}$ & $\mathrm{FEV}_{1}$ (L) & $\begin{array}{l}\text { ACQ5 } \\
\text { Score }\end{array}$ & $\begin{array}{l}\text { FEV }_{1} \% \\
\text { predicted (\%) }\end{array}$ & FEV $_{1}$ (L) & $\begin{array}{l}\text { ACQ5 } \\
\text { Score }\end{array}$ \\
\hline 121001 & KB003 & $40.55(F)$ & 58.62 & 1.53 & 1.0 & 79.69 & 2.08 & 3.4 \\
\hline 150002 & KB003 & $31.52(\mathrm{~F})$ & 53.26 & 1.39 & 4.0 & 74.33 & 1.94 & 2.2 \\
\hline 401002 & KB003 & $29.55(F)$ & 43.13 & 1.13 & 4.0 & 70.61 & 1.85 & 4.2 \\
\hline 505001 & KB003 & 33.95 (M) & 50.92 & 1.66 & 3.2 & 48.47 & 1.58 & 2.4 \\
\hline 508005 & KB003 & $30.83(\mathrm{M})$ & 46.58 & 2.11 & 2.6 & 64.02 & 2.90 & 0.8 \\
\hline 606002 & KB003 & $23.14(F)$ & 52.04 & 1.53 & 1.2 & 63.61 & 1.87 & 1.8 \\
\hline $\begin{array}{l}149003 \\
\text { (ET after W8) }\end{array}$ & KB003 & $29.41(F)$ & 39.78 & 1.09 & 3.8 & 47 & 1.29 & 1.6 \\
\hline $\begin{array}{l}602004 \\
\text { (ET after W8 }\end{array}$ & KВ003 & $28.31(F)$ & 59.69 & 1.94 & 3.0 & 44.31 & 1.44 & 3.0 \\
\hline 130001 & Placebo & $28.11(F)$ & 47.46 & 1.31 & 2.0 & 36.59 & 1.01 & 2.4 \\
\hline 505003 & Placebo & $33.96(F)$ & 38.97 & 1.06 & 2.6 & 45.59 & 1.24 & 1.6 \\
\hline
\end{tabular}

asthma are less clear and remain speculative. It is possible that lower concentrations of GM-CSF are needed for an antiapoptotic effect on eosinophils than on

Table 4 Summary of adverse events

\begin{tabular}{|c|c|c|c|}
\hline $\begin{array}{l}\text { System organ class } \\
\text { preferred term }\end{array}$ & $\begin{array}{l}\text { KB003 } \\
(\mathrm{n}=78)\end{array}$ & $\begin{array}{l}\text { Placebo } \\
(n=82)\end{array}$ & $\begin{array}{l}\text { Total } \\
(\mathrm{n}=160)\end{array}$ \\
\hline $\begin{array}{l}\text { Participants reporting at } \\
\text { least } 1 \text { infusion-related } \\
\text { reaction }\end{array}$ & 4 & 2 & 6 \\
\hline $\begin{array}{l}\text { All infusion-related reactions } \\
\text { reported }\end{array}$ & 6 & $10^{*}$ & 16 \\
\hline $\begin{array}{l}\text { General disorders and } \\
\text { administration site } \\
\text { conditions }\end{array}$ & 0 & 5 & 5 \\
\hline Fatigue & 0 & 2 & 2 \\
\hline Influenza-like illness & 0 & 2 & 2 \\
\hline Infusion site pain & 0 & 1 & 1 \\
\hline Gastrointestinal disorders & 1 & 2 & 3 \\
\hline Diarrhoea & 0 & 0 & 0 \\
\hline Nausea & 1 & 0 & 1 \\
\hline Tongue pruritus & 0 & 2 & 2 \\
\hline Investigations & 1 & 0 & 1 \\
\hline $\begin{array}{l}\text { Body temperature } \\
\text { increased }\end{array}$ & 1 & 0 & 1 \\
\hline Nervous system disorder & 3 & 0 & 3 \\
\hline Dizziness & 1 & 0 & 1 \\
\hline Headache & 2 & 0 & 2 \\
\hline Psychiatric disorders & 0 & 1 & 1 \\
\hline Anxiety & 0 & 1 & 1 \\
\hline $\begin{array}{l}\text { Skin and subcutaneous } \\
\text { tissue disorder }\end{array}$ & 1 & 2 & 3 \\
\hline Rash & 1 & 2 & 3 \\
\hline
\end{tabular}

Events are tabulated by each incidence; a reaction may have occurred multiple times in a single participant.

Source: Listing 16.2.7.3 (appendix 16.2).

*Nine of the 10 events reported for the placebo group occurred in a single participant. neutrophils: $100 \mathrm{pg} / \mathrm{mL}$ vs $100 \mathrm{ng} / \mathrm{mL}$, respectively. ${ }^{18} 38$ Thus, in eosinophilic asthma where the eosinophil but not neutrophil numbers are high, the levels of GM-CSF in the lungs and airways may be very low $(\mathrm{pg} / \mathrm{mL})$ but still effective on eosinophils, and these low GM-CSF levels might have been neutralised at $400 \mathrm{mg}$ dosing of KB003. Conversely, in neutrophilic asthma, where antiapoptosis of neutrophils may be important, the GM-CSF levels in lungs/airways required for such an effect may have to be higher $(\mathrm{ng} / \mathrm{mL})$. Higher amounts of $\mathrm{KB} 003$ may therefore be needed to neutralise these higher levels of GM-CSF in neutrophilic asthma. In addition, the duration of exposure of inflammatory cell precursors in asthmatics to GM-CSF may determine their differentiation into different effector cells. ${ }^{39}$ The duration of neutralisation of GM-CSF needed for effects on neutrophils versus eosinophils may be different and may require different concentrations of injected antibody. If neutrophil generation or activation requires only a short exposure to GM-CSF, then neutralisation by KB003 will need to be maintained constantly and may require higher or more frequent dosing than the regimen we used in our study. Finally, it is possible that the priming and activation of eosinophils and neutrophils in asthma may occur not only via the GM-CSF pathway, or that it occurs in different 'compartments' of the body (eg, submucosa vs airway lumen vs circulation). For example, it has been reported that baseline airway inflammation in intrinsic and extrinsic asthma is characterised by eosinophilic inflammation and the presence of the Th1 cytokine interferon $\gamma$, and that GM-CSF treatment allows eosinophils to respond to lower concentrations of eotaxin via integrin activation and induction of PKCßII-mediated L-plastin phosphorylation. ${ }^{40}$ Given this, one of the limitations of the present study is that we did not measure levels of GM-CSF in blood or the lung compartment. 
Table 5 Summary of all serious adverse events

\begin{tabular}{|c|c|c|c|}
\hline $\begin{array}{l}\text { System organ class } \\
\text { preferred term }\end{array}$ & $\begin{array}{l}\text { KB003 } \\
(n=78)\end{array}$ & $\begin{array}{l}\text { Placebo } \\
(n=82)\end{array}$ & $\begin{array}{l}\text { Total } \\
(n=160)\end{array}$ \\
\hline $\begin{array}{l}\text { Participants reporting } \\
\text { at least } 1 \text { serious } \\
\text { adverse event }\end{array}$ & 5 & 2 & 7 \\
\hline $\begin{array}{l}\text { All serious adverse } \\
\text { events reported* }\end{array}$ & 6 & 4 & 10 \\
\hline Cardiac disorders & 1 & 0 & 1 \\
\hline $\begin{array}{l}\text { Acute myocardial } \\
\text { infarction }\end{array}$ & 1 & 0 & 1 \\
\hline $\begin{array}{l}\text { Gastrointestinal } \\
\text { disorders }\end{array}$ & 0 & 1 & 1 \\
\hline Diarrhoea & 0 & 1 & 1 \\
\hline $\begin{array}{l}\text { General disorders and } \\
\text { administrative } \\
\text { conditions }\end{array}$ & 0 & 1 & 1 \\
\hline $\begin{array}{l}\text { Thrombosis in } \\
\text { device }\end{array}$ & 0 & 1 & 1 \\
\hline $\begin{array}{l}\text { Immune system } \\
\text { disorders }\end{array}$ & 0 & 1 & 1 \\
\hline $\begin{array}{l}\text { Anaphylactic } \\
\text { reactions }\end{array}$ & 0 & 1 & 1 \\
\hline $\begin{array}{l}\text { Infections and } \\
\text { Infestations }\end{array}$ & 3 & 1 & 4 \\
\hline Appendicitis & 1 & 0 & 1 \\
\hline Arthritis bacterial & 0 & 1 & 1 \\
\hline Pneumonia & 2 & 0 & 2 \\
\hline Psychiatric disorders & 1 & 0 & 1 \\
\hline Suicide attempt & 1 & 0 & 1 \\
\hline $\begin{array}{l}\text { Respiratory, thoracic } \\
\text { and mediastinal } \\
\text { disorders }\end{array}$ & 1 & 0 & 1 \\
\hline Hypoxia* $^{*}$ & 1 & 0 & 1 \\
\hline
\end{tabular}

Source: Listing 16.2.7.5 (appendix 16.2).

*Hypoxia was reported as a separate event concurrent with one of the pneumonia cases.

Nasopharyngitis, upper respiratory tract infection and headache were the only AEs that occurred with an overall incidence rate of $5 \%$ or greater. Among these, nasopharyngitis was the only event that occurred in more participants in the KB003 group than in the placebo group (6.4\% vs $4.9 \%$, respectively). All infusionrelated reactions were either self-limiting or were treated with medication and resolved without sequelae. Ten SAEs were reported during the study, none of which were considered related to the study drug (table 5). All doses were generally well tolerated, with no safety signals of concern.

Importantly, there was no evidence of granulocytopenia (ANC $<1000$ ), monocytopenia, severe infusion reactions or pattern of AEs. There were no laboratory changes suggestive of serious or unusual infections. As part of the PAP pharmacovigilance programme for this study, SP-D, lactate dehydrogenase, oxygen saturation, chest X-rays and $\geq 20 \%$ decrease from baseline in $\mathrm{FEV}_{1}$ in the absence of acute bronchoconstriction were monitored for each participant. No observations indicative of signs or symptoms of PAP occurred during the treatment period or during the 3-month safety follow-up period. Indeed, spontaneously occurring and therapy-induced neutralising anti-GM-CSF antibodies have been reported both in healthy adults and in diseased populations without significant safety concerns noted. Low titres of anti-GM-CSF autoantibodies have been reported in the sera of $10-30 \%$ of healthy adults, ${ }^{27}$ and anti-GM-CSF has also been reported to be the dominant anticytokine activity in human intravenous immunoglobulin preparations from healthy human volunteers. $^{41}$

Finally, using a predose/postdose ratio analysis, 7 of 77 participants in the KB003 group had an apparent confirmed emergent immune response to KB003 compared with 4 of 77 participants in the placebo group. The average serum exposure to KB003 derived from the post hoc estimates of the population PK model was comparable in patients with asthma (study KB003-04) and healthy subjects (study KB003-01), and showed an approximately linear increase in $\mathrm{C}_{\max }$ and $\mathrm{AUC}$ with increasing dose. The $\mathrm{T}_{1 / 2}$ of KB003 ranged from 639 to $808 \mathrm{~h}$ across the dose range in both studies.

In summary, the primary objective of the study, which was improvement in lung function with KB003 administration in patients with asthma inadequately controlled by corticosteroids, was not met in the overall population. Analyses of $\mathrm{FEV}_{1}$ in prespecified groups of participants treated with KB003 compared with placebo showed improvements over 24 weeks at a number of time points in patients with eosinophilic asthma (defined as those having blood eosinophil counts $\geq 0.3 \mathrm{GI} / \mathrm{L}$ at baseline), in participants who demonstrated high $(\geq 20 \%) \mathrm{FEV}_{1}$ reversibility at baseline, and in participants with a baseline per cent predicted $\mathrm{FEV}_{1} \leq 50 \%$, but not in other phenotypes. Further studies are required to select a dose of KB003, and a candidate asthma phenotype, for evaluating the role of GM-CSF in severe asthma or other airway conditions.

\section{Author affiliations}

${ }^{1}$ Drug Development Consultant, San Francisco, California, USA

${ }^{2}$ Barlicki University Hospital, Medical University of Lodz, Lodz, Poland

${ }^{3}$ InterMune, Inc., Brisbane, California, USA

${ }^{4}$ Glenmark Pharmaceuticals, Mahwah, New Jersey, USA

${ }^{5}$ Medicines Evaluation Unit, University of Manchester, University Hospital of South Manchester Foundations Trust, Manchester, UK

${ }^{6}$ Chiltern International, Berkshire, UK

Contributors JAL, GY, NAM and BS developed the study. CKO, MC, PK, DS and NAM conducted and supervised the study. BS analysed the data. NAM wrote the manuscript approved by all coauthors. Kalobios, Chiltern and study sites did the study design, execution and collection of data. Analysis and interpretation of data was done by Chiltern, Kalobios and external advisors. Kalobios decided to publish the data.

Funding Kalobios Pharmaceuticals.

Competing interests NAM, GY and CKO were Kalobios employees during the study conduct.

Patient consent Obtained.

Provenance and peer review Not commissioned; externally peer reviewed. 
Data sharing statement No additional data are available.

Open Access This is an Open Access article distributed in accordance with the Creative Commons Attribution Non Commercial (CC BY-NC 4.0) license, which permits others to distribute, remix, adapt, build upon this work noncommercially, and license their derivative works on different terms, provided the original work is properly cited and the use is non-commercial. See: http:// creativecommons.org/licenses/by-nc/4.0/

\section{REFERENCES}

1. Moore WC, Meyers DA, Wenzel SE, et al. Identification of asthma phenotypes using cluster analysis in the Severe Asthma Research Program. Am J Respir Crit Care Med 2010;181:315-23.

2. Akinbami LJ, Sullivan SD, Campbell JD, et al. Asthma outcomes: healthcare utilization and costs. J Allergy Clin Immunol 2012;129(3 Suppl):S49-64.

3. Wenzel SE, Schwartz LB, Langmack EL, et al. Evidence that severe asthma can be divided pathologically into two inflammatory subtypes with distinct physiologic and clinical characteristics. Am J Respir Crit Care Med 1999;160:1001-8.

4. Gibson PG, Simpson JL, Saltos N. Heterogeneity of airway inflammation in persistent asthma: evidence of neutrophilic inflammation and increased sputum interleukin-8. Chest 2001;119:1329-36.

5. Douwes J, Gibson P, Pekkanen J, et al. Non-eosinophilic asthma: importance and possible mechanisms. Thorax 2002;57:643-8.

6. Nadif R, Siroux V, Oryszczyn MP, et al. Heterogeneity of asthma according to blood inflammatory patterns. Thorax 2009;64:374-80.

7. Baines KJ, Simpson JL, Wood LG, et al. Systemic upregulation of neutrophil $\alpha$-defensins and serine proteases in neutrophilic asthma. Thorax 2011;66:942-7.

8. Molfino NA, Gossage D, Kolbeck R, et al. Molecular and clinical rationale for therapeutic targeting of interleukin-5 and its receptor. Clin Exp Allergy 2012;42:712-37.

9. Castro M, Wenzel SE, Bleecker ER, et al. Benralizumab, an anti-interleukin 5 receptor $\alpha$ monoclonal antibody, versus placebo for uncontrolled eosinophilic asthma: a phase $2 \mathrm{~b}$ randomized dose-ranging study. Lancet Respir Med 2014;2:879-90.

10. Newcomb DC, Peebles RS Jr. Th17-mediated inflammation in asthma. Curr Opin Immunol 2013;25:755-60.

11. Wakashin H, Hirose K, Iwamoto I, et al. Role of IL-23-Th17 cell axis in allergic airway inflammation. Int Arch Allergy Immunol 2009;149 (Suppl 1):108-12.

12. Soloperto M, Mattoso VL, Fasoli A, et al. A bronchial epithelial cell-derived factor in asthma that promotes eosinophil activation and survival as GM-CSF. Am J Physiol 1991;260(6 Pt 1):L530-8.

13. Broide $\mathrm{DH}$, Firestein GS. Endobronchial allergen challenge in asthma. Demonstration of cellular source of granulocyte macrophage colony-stimulating factor by in situ hybridization. $J$ Clin Invest 1991;88:1048-53.

14. Mattoli S, Marini M, Fasoli A. Expression of the potent inflammatory cytokines, GM-CSF, IL6, and IL8, in bronchial epithelial cells of asthmatic patients. Chest 1992;101(3 Suppl):27S-9S.

15. Saha S, Doe C, Mistry V, et al. Granulocyte-macrophage colony-stimulating factor expression in induced sputum and bronchial mucosa in asthma and COPD. Thorax 2009;64:671-6.

16. Duncan CJ, Lawrie A, Blaylock MG, et al. Reduced eosinophil apoptosis in induced sputum correlates with asthma severity. Eur Respir J 2003;22:484-90.

17. Laan M, Prause O, Miyamoto M, et al. A role of GM-CSF in the accumulation of neutrophils in the airways caused by IL-17 and TNF-alpha. Eur Respir J 2003;21:387-93.

18. Esnault S, Malter JS. Granulocyte macrophage-colony-stimulating factor mRNA is stabilized in airway eosinophils and peripheral blood eosinophils activated by TNF-alpha plus fibronectin. $J$ Immunol 2001:166:4658-63.

19. Woolley KL, Adelroth E, Woolley MJ, et al. Granulocyte-macrophage colony-stimulating factor, eosinophils and eosinophil cationic protein in subjects with and without mild, stable, atopic asthma. Eur Respir $J$ 1994:7:1576-84.

20. Hamilton JA. GM-CSF in inflammation and autoimmunity. Trends Immunol 2002;23:403-8.

21. Kotsimbos AT, Humbert M, Minshall E, et al. Upregulation of alpha GM-CSF-receptor in nonatopic asthma but not in atopic asthma. J Allergy Clin Immunol 1997;99:666-72.

22. Simpson JL, Grissell TV, Douwes J, et al. Innate immune activation in neutrophilic asthma and bronchiectasis. Thorax 2007;62:211-18.

23. Larsson S, Löfdahl CG, Linden M. IL-2 and IL-4 counteract budesonide inhibition of GM-CSF and IL-10, but not of IL-8, IL-12 or TNF-alpha production by human mononuclear blood cells. Br J Pharmacol 1999;127:980-6.

24. Ohta K, Yamashita N, Tajima M, et al. Diesel exhaust particulate induces airway hyperresponsiveness in a murine model: essential role of GM-CSF. J Allergy Clin Immunol 1999;104:1024-30.

25. Yamashita $\mathrm{N}$, Tashimo $\mathrm{H}$, Ishida $\mathrm{H}$, et al. Attenuation of airway hyperresponsiveness in a murine asthma model by neutralization of granulocyte-macrophage colony-stimulating factor (GM-CSF). Cell Immunol 2002;219:92-7.

26. Vlahos R, Bozinovski S, Chan SP, et al. Neutralizing granulocyte/ macrophage colony-stimulating factor inhibits cigarette smoke-induced lung inflammation. Am J Respir Crit Care Med 2010;182:34-40.

27. Revoltella RP, Laricchia-Robbio L, Moscato $S$, et al. Natural and therapy-induced anti-GM-CSF and anti-G-CSF antibodies in human serum. Leuk Lymphoma 1997;26(Suppl 1):29-34.

28. Uchida K, Nakata K, Suzuki T, et al. Granulocyte/macrophagecolony-stimulating factor autoantibodies and myeloid cell immune functions in healthy subjects. Blood 2009;113:2547-56.

29. Kitamura $\mathrm{T}$, Tanaka N, Watanabe J, et al. Idiopathic pulmonary alveolar proteinosis as an autoimmune disease with neutralizing antibody against granulocyte/macrophage colony-stimulating factor. J Exp Med 1999;190:875-80.

30. Nair P, Pizzichini MM, Kjarsgaard M, et al. Mepolizumab for prednisone-dependent asthma with sputum eosinophilia. $N$ Engl $J$ Med 2009;360:985-93.

31. Juniper EF, O'Byrne PM, Guyatt GH, et al. Development and validation of a questionnaire to measure asthma control. Eur Respir J 1999;14:902-7.

32. Honda $\mathrm{Y}$, Kuroki $\mathrm{Y}$, Matsuura $\mathrm{E}$, et al. Pulmonary surfactant protein $\mathrm{D}$ in sera and bronchoalveolar lavage fluids. Am J Respir Crit Care Med 1995;152(6 Pt 1):1860-6.

33. Brasch F, Birzele J, Ochs M, et al. Surfactant proteins in pulmonary alveolar proteinosis in adults. Eur Respir J 2004;24:426-35.

34. Ortega HG, Liu MC, Pavord ID, et al. Mepoluzimab treatment in patients with severe eosinophilic asthma. New Engl J Med 2014;371:1198-207.

35. Wenzel SE, Barnes PJ, Bleecker ER, et al. A randomized, double-blind, placebo-controlled study of tumor necrosis factor-alpha blockade in severe persistent asthma. Am J Respir Crit Care Med 2009;179:549-58.

36. Corren J, Busse W, Meltzer EO, et al. A randomized, controlled, phase 2 study of AMG 317, an IL-4Ralpha antagonist, in patients with asthma. Am J Respir Crit Care Med 2010;181:788-96.

37. Castro M, Mathur S, Hargreave F, et al. Reslizumab for poorly controlled, eosinophilic asthma: a randomized, placebo-controlled study. Am J Respir Crit Care Med 2011;184:1125-32.

38. Kobayashi T, Takaku Y, Kikuchi I, et al. Eosinophils do not enhance the trans-basement-membrane migration of neutrophils. Int Arch Allergy Immunol 2007;143(Suppl 1):38-43.

39. Hodge JM, Kirkland MA, Aitken CJ, et al. Osteoclastic potential of human CFU-GM: biphasic effect of GM-CSF. J Bone Miner Res 2004;19:190-9.

40. Pazdrak K, Young TW, Straub C, et al. Priming of eosinophils by GM-CSF is mediated by protein kinase Cbetall-phosphorylated L-plastin. J Immunol 2011;186:6485-96.

41. Svenson M, Hansen MB, Ross C, et al. Antibody to granulocytemacrophage colony-stimulating factor is a dominant anti-cytokine activity in human IgG preparations. Blood 1998;91:2054-61. 